Vietnam Journal of Mechanics, VAST, Vol.29, No. 2 (2007), pp. $83-97$

\title{
USING BETTS-MILLER-JANJIC CONVECTIVE PARAMETERIZATION SCHEME IN H14-31 MODEL TO FORECAST HEAVY RAINFALL IN VIETNAM
}

\author{
Vu Thanh Hang, KieU Thi Xin \\ Vietnam National University of Hanoi
}

\begin{abstract}
According to Krishnamurti, improvements of physical parameterizations will mainly affect simulations for the tropics [10]. The study of William A. Gallus Jr. showed that the higher the model resolution and more detailed convective parameterizations, the better the skill in quantitative precipitation forecast (QPF) in general [16]. The quality of precipitation forecast is so sensitive to convective parameterization scheme (CPS) used in the model as well as model resolution. The fact shows that for high resolution regional model like H14-31 CPS based on low-level moisture convergence as Tiedtke did not give good heavy rainfall forecast in Vietnam. In this paper we used the scheme of Betts-Miller-Janjic (BMJ) based on the convective adjustment toward tropical observationally structures in reality instead of Tiedtke in H14-31. Statistical verification results and verification using CRA method of H14-31 of two CPSs for seperated cases and for three rain seasons (2003-2005) shows that heavy rainfall forecast of H14-31/BMJ is better than one of H14-31/TK for Vietnam-South China Sea. CRA verification also shows that it is possible to say that heavy rainfall forecast skill of H14-31/BMJ in tropics is nearly similar to the skill of LAPS of Australia.
\end{abstract}

\section{INTRODUCTION}

Numerical Weather Prediction (NWP) in general and rainfall forecast in the tropics in particular are difficult problems for meteorologists over the world. Variations in meteorological fields in the tropics are very small in comparison with one in the extratropics so that to show the same forecast skill we need to achieve much higher forecast accuracy in the tropics than in the extratropics. According to Krishnamurti, improvements of physical parameterizations play important roles in simulations for the tropics [10]. Increasement of resolution in horizontal and vertical grid spacings is also important to increase forecast skill in the tropics, because physics in the tropical atmosphere are governed by meso- and small-scale processes such as shallow convection, deep convection, latent heat release... The study of William A. Gallus Jr. showed that the higher the model resolution and more detailed convective parameterizations, the better the skill in QPF in general [16]. The quality of precipitation forecast is so sensitive to CPS used in the model, parameters in CPS as well as model resolution. There is no scheme which is well suitable for every weather situiations currently.

The research results of the National level Project Grant of ID: DTDL-2000/02 show that the version of High resolution Regional Model (HRM) with $14 \mathrm{~km}$ in horizontal and 31 levels in vertical (indicated as H14-31) is suitable for NWP in Vietnam [15]. The H14-31 used Tiedtke scheme (indicated as H14-31/TK) is now run operationally at the National Center for Hydro-Meterological Forecasting. 
However, the verification results of simulated rainfall by H14-31/TK show that deep convection caused 70-80\% of heavy precipitation amount in our region and normally $\mathrm{H} 14$ $31 /$ TK overestimated rain of low thresholds and underestimated rain of high thresholds. The Tiedtke scheme is based on low-level moisture convergence [13]. This mechanism is the main one for large- and meso alpha- scale processes producing rainfall while tropical deep convection caused heavy rainfall is of about $10 \mathrm{~km}$ horizontal scale.

The higher the resolution is, like. H14-31, the better the model can capture the atmospheric instability. The purpose of this paper is to choose a suitable CPS for H14-31 to improve heavy rainfall forecast in Vietnam. Some convection schemes have been tested. The theoretical basis of BMJ scheme and rainfall forecast of H14-31 using BMJ scheme (indicated as H14-31/BMJ) are introduced now. All rainfall forecast results of H14-31/BMJ and of H14-31/TK are verified by comparision with observations.

\section{THE CONVECTIVE ADJUSTMENT SCHEME OF BETTS-MILLER-JANJIC}

The BMJ CPS is based on the simultaneous relaxation of model temperature and moisture fields towards observed quasi-equilibrium thermodynamic structures in the tropics $[8]$.

\subsection{The observed thermodynamic structures in the tropical atmosphere}

One of the key purposes of the GATE experiment was to study complicated organized deep convection in the tropics to test and develop CPSs for numerical models [3]. The primary objective of the CPS is to ensure that the local vertical temperature and moisture structures, which are strongly constrained by convection, be realistic [5]. The concept of a quasi-equilibrium between the cloud field and the large-scale forcing has been well estabished by Betts for shallow convection and by Arakawa and Schubert for deep clouds $[1,2]$. This means that convective regions have characteristic temperature and moisture structures which can be documented observationally, and used as the basis of a convective adjustment procedure.

Manabe et al. suggested the deep convective adjustment toward moist adiabatic for deep convection while the tropical atmosphere does not approach a moist adiabatic equilibrium structure in the presence of deep convection [11]. This implies that on the grid scale a model always maintains a realistic vertical temperature and moisture structure in the presence of convection.

The next step is that how can show observationally that different convective regimes have different quasi-equilibrium thermodynamic structures to maintain the quasi-equilibrium between the subgrid-scale cloud and grid scale processes. Betts established theoretical basis from a series of data sets from GATE, BOMEX, ATEX, which is based on the saturation point (abbreviated $s p$ and determined by temperature and pressure $\left(T^{*}, p^{*}\right)$ at the lifting condensation level), from which a parameters set suitable for both shallow and deep convection in a global model is established [4].

a) Deep convection in the tropics

Convective soundings over tropical ocean (for example the eye wall of a typhoon) show a temperature structure which nearly parallels a moist virtual adiabat $\left(\theta_{E S V}\right)$ below 600 $\mathrm{mb}$, and has $\theta_{E S}$ increasing above, with a nearly saturated atmosphere $\left(p^{*}-p=P=-15\right.$ 
$\mathrm{mb}$ ). Inside the eyewall, the strong subsidence has produced a very stable thermal structure but the $s p$ structure is very close to the temperature structure of the eyewall (due to the subsidence of air originally saturated at the eyewall temperature. The midtropospheric subsidence within the eye is $60 \mathrm{mb}$ ). Thus, the temperature structure of the eyewall is confirmed by two independent composites. The mean temperature structure is quite far from moist adiabatic, but quite close to the $\theta_{E S V}$ isopleth up to the freezing level. In tropical convective disturbances (weaker than the typhoon), $P=-30 \mathrm{mb}$ corresponds to a relative humidity of $85 \%$ at $800 \mathrm{mb}, 75 \%$ at $500 \mathrm{mb}$ and $32 \%$ at $200 \mathrm{mb}$ at tropical temperatures. This vertical temperature and moisture structures observed also by soundings over land, are typical of deep convection in the tropics and may be regarded as more representative of deep convective equilibrium than, say, a moist adiabatic temperature structure.

Based on the soundings above, parametric philosophy is given. The moist virtual adiabat (constant $\left.\theta_{E S V}\right)$ has a slope $(d \theta / d z)$ only 0.9 times that of the moist adiabat (constant $\theta_{E S}$ ). That means a marked reduction in buoyancy in the low levels [4]. Thus, $\theta_{E S V}$ shows the critical reference process rather than $\theta_{E S}$ when deep convection appears. In physical terms the atmosphere remains slightly unstable to a moist virtual adiabat so that air rising in vigorous cumulus towers remains buoyant until its cloud water is converted to precipitation-size particles. The parametric theory basis of the Betts scheme is to establish a parametric model for deep convection simply constrains $\theta_{E S}$ to have a minimum near the freezing level, using the moist virtual adiabat $\theta_{E S V}$ as a reference process in the lower atmosphere.

The p structure (related to subsaturation) shows more variability related to important physical processes. The parametric model will simply specify a reference p structure. This reference structure may be thought of as a threshold for the onset of precipitation which is determined from GATE data set.

b) Shallow convection in the tropics

Tropical soundings show that the vertical temperature structure in the conditionally unstable cumulus layer is close to the mixing curve. Thus, for shallow convection the mixing line is the reference profile which is the basis for shallow convective parameterization. Parametric idealization is the coupling of a temperature and dew-point structure of a convective layer to a mixing line. Saturation level pressure $p^{*}(p)$ locates $T(p), T_{D}(p)$ on this mixing line. The scheme parameter $\beta$ represents the intensity of mixing within and between convective layers, defined as

$$
\beta=\frac{d p^{*}}{d p}
$$

Then, the relation between the mean vertical profiles of $\theta$, $q$ and the gradient of the mixing line as follow

$$
\frac{\partial \theta}{\partial p}=\beta\left(\frac{\partial \theta}{\partial p^{*}}\right)_{M}, \quad \frac{\partial q}{\partial p}=\beta\left(\frac{\partial q}{\partial p^{*}}\right)_{M}
$$

$M$ denotes the mixing line. When $\beta=0$ represents a well-mixed layer and the subcloud layer often approaches this structure. $\beta<1$ is a layer not as well mixed. $\beta=1$ is a partially mixed structure in which the $\theta, q$ (or $T, T_{D}$ ) profiles are approximately parallel to the mixing line. $\beta>1$ represents the divergence of $\theta, q$ from the mixing line. In the basical version of the shallow convection adjustment scheme $\beta=1$ is specified from cloud base to cloud top. This means that the lapse rate in the cloud layer is parallel to the mixing 
line with constant subsaturation parameter $p$ since $\partial p / \partial p=\beta-1=0$. The value of $p$ is implicitly determined by the two seperate integral energy constraints on water vapor and enthalpy since we assume shallow convection does not precipitate. A linear approximation to the mixing line is computed between low-level air and air from the level above cloud top. Cloud top is the intersection with the sounding of a moist adiabat through a low-level $\theta_{E}[4,7]$.

\subsection{Theoretical basis of the BMJ convective adjustment scheme}

Based on the above tropical observationally temperature and moisture structure, the BMJ-scheme is designed to adjust the atmospheric temperature and moisture structures back towards a reference quasi-equilibrium thermodynamic structure in the presence of large-scale radiative and advection processes. Two different reference thermodynamic structures are used for shallow and deep convection.

\section{Formal structure}

The large-scale thermodynamic tendency equation can be written as

$$
\frac{\partial \bar{S}}{\partial t}=-V \cdot \nabla \bar{S}-\bar{\omega} \frac{\partial \bar{S}}{\partial p}-g \frac{\partial N}{\partial p}-g \frac{\partial F}{\partial p},
$$

where $\bar{S}$ represents for thermodynamic variables (model variables), $N$ and $F$ are the net radiative and convective fluxes (including the precipitation flux).

The convective flux divergence is parametrized as

$$
-g \frac{\partial F}{\partial p}=\frac{S_{R}-\bar{S}}{\tau},
$$

where $S_{R}$ is the reference quasi-equilibrium thermodynamic structure of $S, \tau$ is a relaxation or adjustment time representative of the convective or mesoscale processes. Considering the large-scale thermodynamic tendency caused due to convection (excluding advection and radiation), and combining (2.3) and (2.4) gives

$$
\frac{\partial \bar{S}}{\partial t}=-\bar{\omega} \frac{\partial \bar{S}}{\partial p}+\frac{S_{R}-\bar{S}}{\tau} .
$$

Near quasi-equilibrium means $\partial \overrightarrow{S / \partial} t \approx 0$ so that $(2.5)$ becomes

$$
S_{R}-\bar{S} \approx \bar{\omega} \frac{\partial \bar{S}}{\partial p} \tau
$$

Values of $\tau$ is found from 1-2 hours give good results in the presence of realistic forcing showed that $\left(S_{R}-\bar{S}\right)$ corresponds to about one hour's forcing by the large-scale fields, including radiation. For deep convection the atmosphere remains slightly cooler and moister than $S_{R}$. For small $\tau$, the atmosphere will approach $S_{R}$ so that we may substitute $\bar{S} \approx S_{R}$ in the vertical advection term, giving

$$
S_{R}-\bar{S} \approx \bar{\omega} \frac{\partial S_{R}}{\partial p} \tau
$$

Combine (2.7) and (2.4) and take integral we receive the convective fluxes which can be approximately expressed as (2) in the form

$$
F=\int \frac{\left(S_{R}-\bar{S}\right)}{\tau} \frac{d p}{g} \approx \int \bar{\omega} \frac{\partial \dot{S}_{R}}{\partial p} \frac{d p}{g} .
$$


Thus, the structure of the convective fluxes is closely related to the structure of the specified reference profile $S_{R}$. By adjusting towards an observationally realistic thermodynamic structure $S_{R}$, we simultaneously constrain the convective fluxes including precipitation to have a structure similar to those derived from (2.3), or its simplified form (2.8).

Substitute $p^{*}$ in $(2.7)$ and since $1<\frac{d p_{R}^{*}}{d p}<1.1$ for deep convection so we can get

$$
p_{R}-\bar{p}=p_{R}^{*}-\bar{p}^{*} \approx \bar{\omega} \tau \frac{d p_{R}^{*}}{d p} \approx \bar{\omega} \tau
$$

or

$$
\bar{p}=p_{R}-\bar{\omega} \tau \text {. }
$$

Thus, in the deep convection scheme the grid scale $\bar{p}$ is shifted by the mean vertical advection $\bar{\omega} \tau \mathrm{mb}$ towards saturation from the specified reference state $p_{R}$. Thus, although we specify in the present simple scheme a constant global value of the reference strucutre $p_{R}, \bar{p}$ does have a spatial and temporal variability due to the $\bar{\omega}$ in the presence of deep convection.

The role of convective parametrization in a numerical model in general is to produce precipitation before grid-scale saturation is reached both to simulate the real behaviour of atmospheric convection and also to prevent grid-scale instability associated with a saturated conditionally unstable atmosphere. If the convection scheme is to prevent gridscale saturation, $\bar{p}=0$ from $(2.10)$, there is a constraint on time $\tau, \tau<p_{R} / \omega_{\max }$, in which $\omega_{\max }$ is a typical maximum of vrtical velocity $\omega$ in a major tropical disturbance.

\section{Adjustment procedure}

Change of the thermodynamic structure $\bar{S}$ is considered due to the large-scale advection terms, radiation and surface fluxes. Cloud top is then found using a moist adiabat through the low-level $\theta_{E}$. Cloud top height intially distinguishes shallow from deep convection. Different reference profiles are established for shallow and deep convection which satisfy different energy integral constraints. The convective adjustment $\left(S_{R}-\bar{S}\right) / \tau$ is then applied to the separate temperature and moisture fields as two tendencies

$$
\begin{aligned}
& \left(\frac{\partial \bar{T}}{\partial t}\right)_{C}=\frac{T_{R}-\bar{T}}{\tau} \\
& \left(\frac{\partial \bar{q}}{\partial t}\right)_{C}=\frac{q_{R}-\bar{q}}{\tau}
\end{aligned}
$$

(subcript $c$ for convection). The main problem now is how to determine the two reference temperature and moisture $\left(T_{R}, q_{R}\right)$.

Determination of reference thermodynamic profiles $S_{R}\left(T_{R}, q_{R}\right)$

The essence of this convective adjustment scheme is to estimate the reference profiles in which shallow and deep convection is distinguished by cloud top.

a) Shallow convection and computation of shallow convection reference profile: For shallow convection the reference profile $S_{R}$ (denoted as $T_{R-s h}$ or $q_{R-s h}$ ) is constructed to satisfy the two seperate energy constraints:

$$
\int_{p_{B}}^{p_{T}} c_{p}\left(T_{R-s h}-\bar{T}\right) d p=0, \quad \int_{p_{B}}^{p_{T}} L\left(q_{R-s h}-\bar{q}\right) d p=0
$$


so that the condensation (and precipitation) rates are zero when integrated from cloud base $p_{B}$ to cloud top $p_{T}$. This implies that the shallow convection scheme does not give precipitattion, but redistributes heat and moisture in the vertical, in which intensity of mixing $\beta$ is a function of mixing slope since the mixing line slope governs the cloud top instability [7].

a1) First-guess profile: From (2.2), the slope of the mixing line is computed from the properties of air at the level $p_{B}$ and the level above cloud top $p_{T^{+}}$. This is done by first finding the saturation point $s p$ 'on the mixing line corresponding to an equal mixture of air from the levels $p_{B}$ and $p_{T^{+}}$. The level $p_{T^{+}}$, denoted (2.1) is then used to give a linearized mixing line slope in the lower troposphere using

$$
M=\left\{\theta_{E}(1)-\theta_{E}(B)\right\} /\left\{p_{S L}(1)-p_{S L}(B)\right\},
$$

in which $p_{S L}(1)$ and $p_{S L}(B)$ are corresponding saturation level pressures above cloud top and cloud base. Constant $M$ in the current scheme is timed with a coefficient 0.8. $p_{B}$ is the level where saturated equivalent potential temperature $\theta_{E S}(B)$ is maximum in the air column. This level is cloud base. Cloud top is the level where the temperature different between the environment and the parcel is less than $3^{\circ} \mathrm{C}$. The first-guess temperature profile is specified as parallel to the mixing line (corresponding to $\beta=1$ ) by first estimating as

$$
\theta_{E S}(p)=\theta_{E S}(B)+M\left(p-p_{B}\right)
$$

$\theta_{E S}(p)$ is inverted to give $(T, p)$ together with $\mathcal{P}$ (a first-guess independent of $p$ ) gives the $s p$ and hence specific humidity. It means that the first-guess profiles of potential temperature and humidity are determined with a coefficient 0.8 of $M$.

a2) Temperature and moisture correction: Shallow convection does not precipitate so that the integrals of $c_{p} T$ and $L q$ are seperately conserved in this layer (follow eq. (2.13)). To ensure this, the first-guess of $T$ and $q$ are corrected at each level by

$$
\begin{gathered}
\Delta T=\left(p_{B}-p_{T}\right)^{-1} \int_{p_{B}}^{p_{T}}\left(T-T_{R-s h}\right) d p, \\
\Delta q=\left(p_{B}-p_{T}\right)^{-1} \int_{p_{B}}^{p_{T}}\left(q-q_{R-s h}\right) d p .
\end{gathered}
$$

By making this correction independent of pressure, we preserve the slope $M$ of the $\theta_{E S}$ profile, and $\mathcal{P}$ independent of pressure. For shallow convection we have two constraints, it is not necessary to constraint $\mathcal{P}$. After applying the corrections (2.16) and (2.17), the adjustment closely conserves the vertically averaged value of $\mathcal{P}$ through the shallow convective layer. 


\section{b) Deep convection and computation of deep convection reference profile:}

For deep convection the reference profile (denoted as $T_{R-d}$ or $q_{R-d}$ ) is constructed to satisfy the total enthalpy constraint:

$$
\int_{p_{B}}^{p_{T}}\left(H_{R-d}-\bar{H}\right) d p=0
$$

where $H=\left(c_{p} T+L q\right)$. In Betts-Miller $p_{B}$ is fixed at $\sigma=0.98$ (it means that the deep convection adjustment is made down to one level above the model surface) [8]. The precipitation rate $R_{d}$ is then given by

$$
R_{d}=\int_{p_{B}}^{p_{T}}\left(\frac{q_{R-d}-\bar{q}}{\tau}\right) \frac{d p}{g}=-\frac{c_{p}}{L} \int_{p_{B}}^{p_{T}}\left(\frac{T_{R-d}-\bar{T}}{\tau}\right) \frac{d p}{g} .
$$

b1) First-guess profile: For deep convection, the potential temperature profile has a minimum $\theta_{E S}(F)$ at the freezing level $p_{F}$. In the layer from cloud base level to freezing level $\left(p_{B}>p>p_{F}\right)$ the saturation virtual equivalent temperature decreases with the gradient of the saturation virtual equivalent temperature $V=\left(\partial \theta_{E S} / \partial p\right)_{\theta_{E S V}}$ multiplied by a weighting coefficient $\alpha$. Thus, the first-guess in deep convection shows the decrease at the low level, it means that in the layer $\left(p_{B}>p>p_{F}\right)$ the profile is determined by

$$
\theta_{E S}=\theta_{E S}(B)+\alpha V\left(p-p_{B}\right) \text {. }
$$

In the layer from freezing level to cloud top $\left(p_{T}<p<p_{F}\right)$ this profile increases back to the environmental $\theta_{E S}$ at cloud top as follows

$$
\theta_{E S}=\theta_{E S}(F)+\left\{\theta_{E S}(T)-\theta_{E S}(F)\right\} \frac{p-p_{T}}{p_{F}-p_{T}} .
$$

Testing using a GATE wave data set showed thar $\alpha=1.5$ gave a realistic tropospheric temperature structure [9]. This reference profile in the low troposphere is therefore slightly unstable to the $\left(\theta_{E S V}\right)$ isopleth, and has a gradient (compared to the dry and moist adiabats) of

$$
\left(\frac{\partial \theta_{E S}}{\partial p}\right)_{R} \approx 0.15\left(\frac{\partial \theta_{E S}}{\partial p}\right)_{\theta}
$$

or equivalent

$$
\left(\frac{\partial \theta}{\partial p}\right)_{R} \approx 0.85\left(\frac{\partial \theta}{\partial p}\right)_{\theta_{E S}}
$$

Then, the moisture profile is found from the temperature profile by specifying a gridpoint mean $\mathcal{P}=\left(p^{*}-p\right)$ at three levels: cloud base $\left(\mathcal{P}_{B}\right)$, the freezing level $\left(\mathcal{P}_{F}\right)$ and cloud top $\left(\mathcal{P}_{T}\right)$ with linear gradients between.

In the lower layer $p_{B}>p>p_{F}$ the saturation depression is determined as

$$
\mathcal{P}(p)=\frac{\left(p_{B}-p\right) \mathcal{P}_{F}+\left(p-p_{F}\right) \mathcal{P}_{B}}{p_{B}-p_{M}}
$$


and for upper layer $p_{T}<p<p_{F}$

$$
\mathcal{P}(p)=\frac{\left(p_{F}-p\right) \mathcal{P}_{T}+\left(p-p_{T}\right) \mathcal{P}_{F}}{\left(p_{F}-p_{T}\right)}
$$

In the present scheme, $\mathcal{P}_{B}=-48 \mathrm{mb}, \mathcal{P}_{F}=-70 \mathrm{mb}$ and $\mathcal{P}_{T}=-22 \mathrm{mb}$ (negative means unsaturated) with $|\mathcal{P}|$ a maximum at the freezing level.

b2) Energy correction:

For deep convection the reference profiles $T(p)$ and $q(p)$ are computed from $\theta_{E S}(p)$ and $\mathcal{P}(p)$ and then need to satisfy the total enthalpy constraint (2.18). The condition (2.18) means that a constant correction $\Delta H^{\prime}$ is applied to the first-guess reference profile at all level (except the cloud top level) as

$$
\Delta H^{\prime}=\Delta H \frac{p_{B}-p_{T}}{p_{B}-p_{T^{-}}},
$$

where $p_{T-}$ is at the level below cloud top. $\Delta H$ in Eq. (2.24) is determined as

$$
\Delta H=\left(p_{B}-p_{T}\right)^{-1} \int_{p_{B}}^{p_{T}}\left(H_{R-d}^{1}-H_{S}\right) d p
$$

where $H_{R-d}^{1}$ is enthalpy from the first-guess reference profile, $H_{S}$ is for the grid point thermodynamic structure.

At each level the temperature field is corrected, with $\mathcal{P}=$ const, so as to change its enthalpy $H=\left(c_{p} T_{R-d}+L q_{R-d}\right)$ by $\Delta H^{\prime}$. Applying no correction at cloud top means that the adjustment scheme corrects the $q$ field at cloud top but not the $T$ field. One iteration is made on this energy correction step to ensure the subsequent adjustment conserving energy to high accuracy.

\section{VERIFICATION OF RAINFALL FORECAST OF H14-31 USING DIFFERENT CONVECTION SCHEMES}

To evaluate the CPS of BMJ in comparision with the scheme of Tiedtke some heavy rainfall forecast cases of H14-31 with both schemes are shown. QPF of H14-31/BMJ are statistically verified using measurements of rain-gauge in VietNam and then compared with the corresponding results of H14-31/TK to choose the more suitable scheme for heavy rainfall forecast by H14-31.

\subsection{Qualitative evaluating heavy rain forecast}

a) Fig. 1 is the smoothly $24 \mathrm{~h}$ accumulated rainfall forecast, started at 00Z21082005 of H14-31/TK (left), H14-31/BMJ (right) and the analysis (middle). This is the heavy rainfall case which happened so quickly in the North of Vietnam on August $22^{\text {nd }} 2005$ causing inundation in a lot of mainly streets in Hanoi.

From Fig. 1 we see that H14-31/BMJ gives rainfall area and the averaged rainfall amount greater than those of H14-31/TK. In the North West region, H14-31/TK estimated the rainfall values varying from $5 \mathrm{~mm}$ to $80 \mathrm{~mm}$ while the rainfall amount of H14-31/BMJ varied from $15 \mathrm{~mm}$ to $50 \mathrm{~mm}$ and in good agreement with observations. In the North East region, H14-31/BMJ also predicted much better rainfall intensity, values vary from $15 \mathrm{~mm}$ to $50 \mathrm{~mm}$ and especially can capture the extreme in coast of Quang Ninh. Besides, H14-31/BMJ detected some areas of small precipitation, which is good in position but 

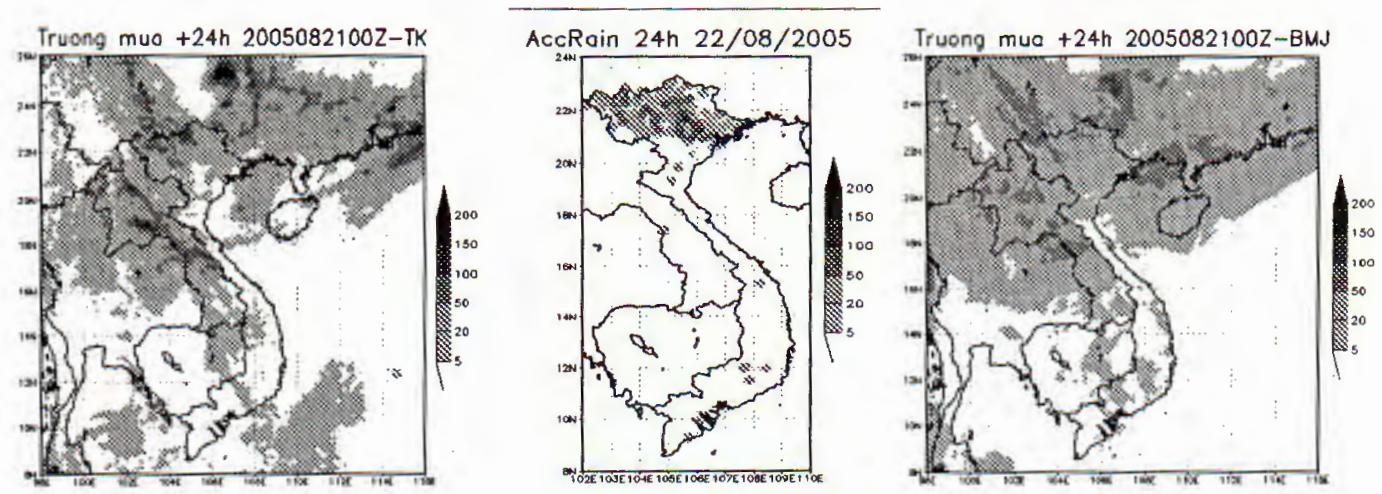

Fig. 1. The 24 h accumulated rainfall forecast of $\mathrm{H} 14-31$, started at $00 \mathrm{Z} 21082005$, using two convection schemes: TK (left), BMJ (right) and analysis (middle)
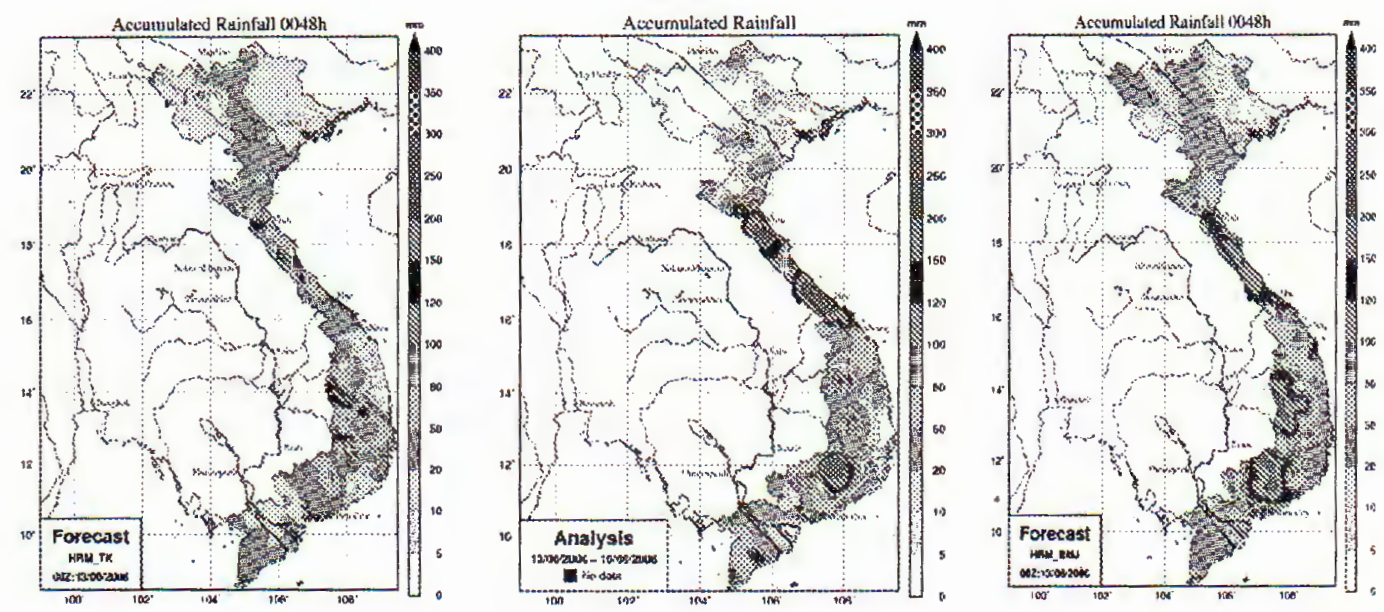

Fig. 2. The $48 \mathrm{~h}$ accumulated rainfall forecast of H14-31, started at 00Z13082006, using two convective parameterization schemes: TK (left), BMJ (right) and analysis (middle)

underestimated in the Southern Central and the South of Vietnam. In this case, we can say that the H4-31/TK forecasted better rain intensity but worser rain location and rain pattern than the H14-31/BMJ. However, the both versions underestimate rainfall.

Figs. 2 and 3 are $48 \mathrm{~h}$ accumulated rainfall forecast of H14-31/TK (left), H14-31/BMJ (right) started at 00Z13082006 and 00Z15082006 respectively and analysis (middle). This large extent heavy rain spell lasted six days (13-16/8/2006) caused by the strong combination of south west monsoon bringing moisture from Bengal bay and ITCZ bringing moisture from South China Sea (only two cases of $48 \mathrm{~h}$ forecast are introduced here). 

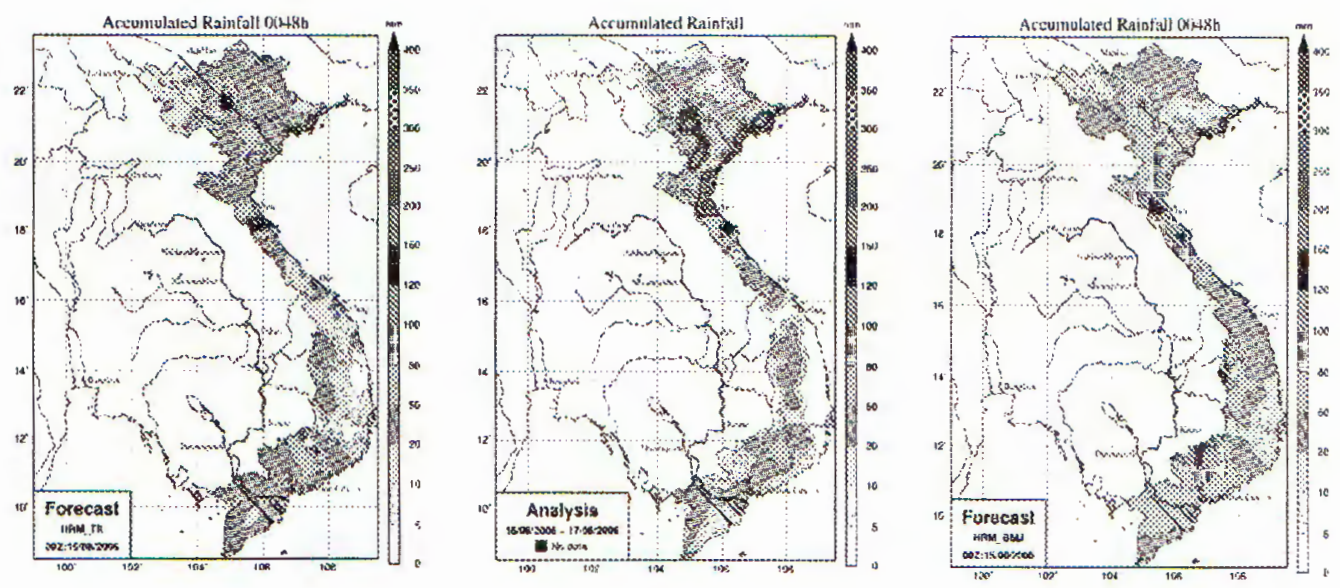

Fig. 3. The $48 \mathrm{~h}$ accumulated rainfall forecast of H14-31, started at 00Z15082006 using two convective parameterization schemes: TK (left), BMJ (right) and analysis (middle)

Comparing the forecast and the analysis of measurements shown in Figs. 2 and 3 we can see that both H14-31/TK and H14-31/BMJ can capture the rainfall areas in the whole of Vietnam but underestimate rainfall.

H14-31/BMJ always provides better results than H14-31/TK especially in the Northern coast and the Central. The total measured rainfall of two days 13-14/8/2006 (Fig. 2 , middle) shows a maximum in the coast of Central. H14-31/BMJ predicts rainfall area (Fig. 2, right) nearly similar to measurements with detection of the maximum rainfall area at the coast, while the H14-31/TK forecasts the area of rain maximum on western of Truong Son moutain (Fig. 2, left) which basically contradict with observation.

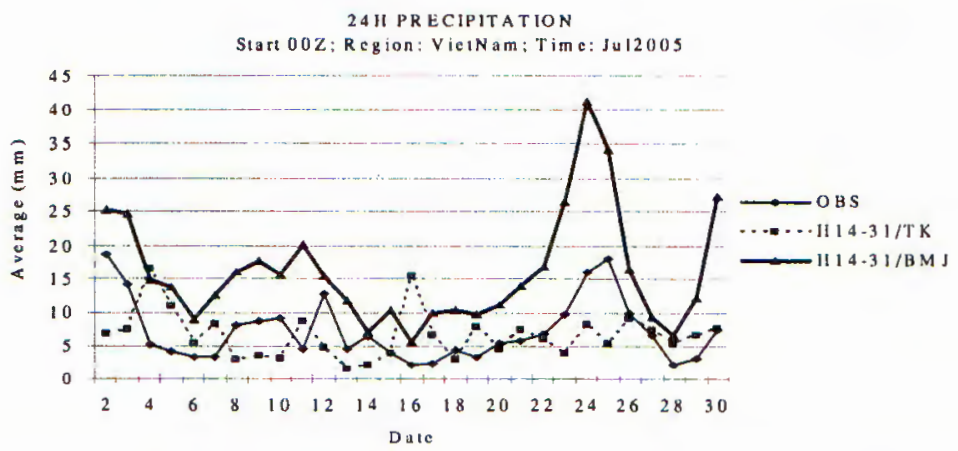

Fig. 4. Time series of daily averaged rain gauge mesurements of July 2005 for the whole of Vietnam and corresponding forecasts of H14-31/BMJ and H14-31/TK

Fig. 3 shows similar results, H14-31/BMJ predicts the maximum rainfall area along the coast of Thanh Hoa-Nghe An (Fig. 3, right) which is corresponding to rain measurements (Fig. 3, middle) while H14-31/TK still forecasts the maximum on western of Truong Son 
moutain. From Fig. 4 illustrating daily averaged rainfall forecast of July 2005 with two versions and rain gauge measurements for the whole of Vietnam we can see that there is no heavy rainfall period in measurements, mainly is medium and light rainfall in the month. There are two days ( $2^{\text {th }}$ a nd $25^{\text {th }}$ July) with rain maximum of only $18 \mathrm{~mm}-19 \mathrm{~mm}$. Comparing forecasts with measurements we can say that for light and medium rain, H1431/BMJ overestimates rain amount, however, determined maxima are in agreement with maxima of measurements. On the contrary, the H14-31/TK usually underestimates rain amount and sometimes shows relative minima while observation shows relative maxima. These results implies that the BMJ sheme can simulate tropical convection and therefore tropical rain better than the TK sheme.

Fig. 5 demonstrates mean error (ME) and mean absolute error (MAE) of $24 \mathrm{~h}$ accumulated rainfall forecast of $\mathrm{H} 14-31 / \mathrm{TK}$ and H14-31/BMJ of July 2005 for the whole of Vietnam and for separated regions with respectively number of surface stations such as: Vietnam (344 stations), the North (200 stations), the Central (83 stations), the South (61 stations). We can see that ME of $\mathrm{H} 14-31 / \mathrm{BMJ}$ of seperated regions is positive and not large for this month (with maximum of $12 \mathrm{~mm} /$ day) while H14-31/TK gives small and positive ME in the North but negative for other regions, especially in the South. MAE of two versions are not much different.
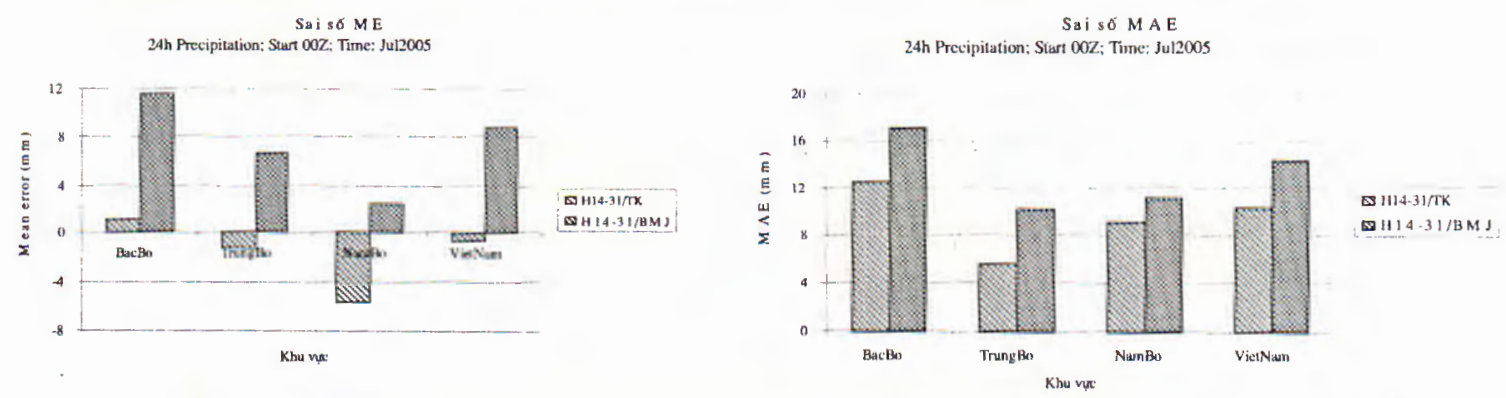

Fig. 5. Mean error (up) and Mean absolute error (down) of $24 \mathrm{~h}$ accumulated rainfall forecast of H14-31/TK $v \mu$ H14-31/BMJ

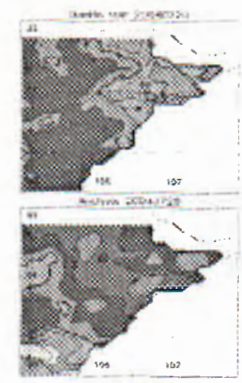

(a): H14-31/TK

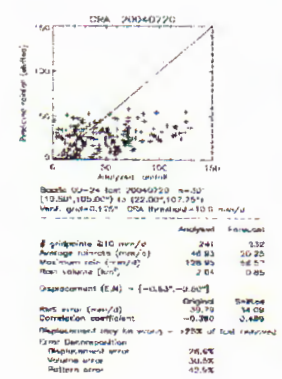

$x$

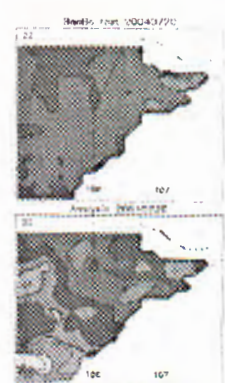

(b): H14-31/BMJ

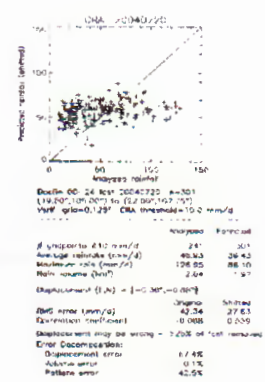

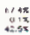

Fig. 6. CRA verification result for $24 \mathrm{~h}$ accumulated rainfall forecast, start at 00220072004 with: (a)-H14-31/TK, (b)- H14-31/BMJ for threshold $\geq 10 \mathrm{~mm} /$ day

The comparing distribution of forecasted precipitation with analysis in Figs. 1 to 3 or statistical scores in Figs. 4 to 5 only can show us the predictability of model but could not suggest us reasons causing prediction errors. Together with improved numerical weather 
forecast models specially concentrated on QPF in the past decade many new verification methods are developed which could provide model developers with special scores to explain reasons causing predition errors to improve model. One of them is CRA method which is introduced in the following section.

\subsection{CRA method and verification of rainfall forecast}

Details of CRA (Contiguous Rainfall Area) method can be seen in the original paper of McBride, Ebert or Kieu Thi Xin et. al $[12,16]$. The CRA method considers that a good QPF should have good forecast in:

Location of rainfall area. The respectively error is displacement error.

Rainfall intensity. The respectively error is volume error.

Pattern of rainfall area. The respectively error is pattern error.

In Vietnam, there is only the North-East area of relative density observations to satisfy CRA verification. So, we perform CRA verification of rain forecast of H14-31 only for the area of $19.5 \mathrm{~N}-22.0 \mathrm{~N}$ and $105.0 \mathrm{E}-107.75 \mathrm{E}$.

Fig. 6 shows one CRA verification results of rainfall forecast with the threshold of $\geq 10$ $\mathrm{mm} /$ day for July $20^{\text {th }}, 2004$ in the North East region. We can see that forecasted rainfall (vertical axis) is often lower than measurements (horizontal axis). The rainfall forecasts of H14-31/BMJ (Fig. 6b) more concentrates around the ideal line (the diagonal line) than those of H14-31/TK (Fig. 6a). A similar example of the date August $22^{\text {nd }}, 2005$ with threshold of $\geq 5 \mathrm{~mm} /$ day is presented in Fig. 7. The scatter plot in it also shows that H14$31 / \mathrm{TK}$ underestimates rain of high thresholds but overestimates rain of low thresholds. However, the rain forecast of H14-31/BMJ distributed more around the ideal line (in Fig. $6,7)$ than one of H14-31/TK implies that the CPS of BMJ could simulate heavy rainfall in this region better than the scheme of Tiedtke.

Table 1. Statistical scores of CRA verification for heavy rainfall forecast of H1431/TK and H14-31/BMJ (averaged of 3 years 2003 - 2005) for the North East and of LAPS (averaged of year 2000) for different regions of Australia

\begin{tabular}{|c|c|c|c|c|c|c|c|c|c|c|}
\hline \multirow{2}{*}{$\begin{array}{l}\text { Thres- } \\
\text { hold }\end{array}$} & \multirow{2}{*}{ Model } & \multirow{2}{*}{$\begin{array}{c}\text { No. } \\
\text { of } \\
\text { CRA }\end{array}$} & \multicolumn{2}{|c|}{ RMSE } & \multicolumn{2}{|c|}{$\begin{array}{l}\text { Comelation } \\
\text { coefticient }\end{array}$} & \multirow{2}{*}{$\begin{array}{l}\text { Dispiac- } \\
\text { cmentersor } \\
(\%)\end{array}$} & \multirow{2}{*}{\multicolumn{2}{|c|}{$\begin{array}{c}\text { Volume } \\
\text { error } \\
\text { (\%) }\end{array}$}} & \multirow{2}{*}{$\begin{array}{l}\text { Pattern } \\
\text { error } \\
(\%)\end{array}$} \\
\hline & & & Original & Shifted & Original & Shifted & & & & \\
\hline \multicolumn{11}{|c|}{ Part I: H14-31, (2003-2005) } \\
\hline \multirow{2}{*}{$\begin{array}{l}\text { Aver- } \\
\text { aged }\end{array}$} & $\mathrm{BMJ}$ & 633 & 33.3 & 24.0 & 0.15 & 0.33 & 46.1 & \multicolumn{2}{|c|}{7.8} & 46.1 \\
\hline & TK & 389 & 39.5 & 28.3 & 0.13 & 0.35 & 42.9 & \multicolumn{2}{|c|}{11.3} & 45.8 \\
\hline \multicolumn{11}{|c|}{ Part U: LAPS $(2000)$} \\
\hline \multirow{5}{*}{$\begin{array}{l}\text { Aver- } \\
\text { aged }\end{array}$} & \multicolumn{5}{|l|}{ Tropics } & 55. \pm 2 & \multicolumn{2}{|c|}{ 3. \pm 1.} & 42 & \pm 1 \\
\hline & \multicolumn{5}{|c|}{ North Easi Edge } & 65. \pm 5 & 3. \pm & & 33 & \pm 4 \\
\hline & \multicolumn{5}{|c|}{ West Edge } & $54 . \pm 3$ & 7. \pm & & 39 & \pm 2 \\
\hline & \multicolumn{5}{|l|}{ Centre } & 41. \pm 1 & 7. \pm & & 52 & \pm 1 \\
\hline & \multicolumn{5}{|c|}{ Whole of Australia } & 50. \pm 1 & 5. \pm & & 45 & \pm 1 \\
\hline
\end{tabular}




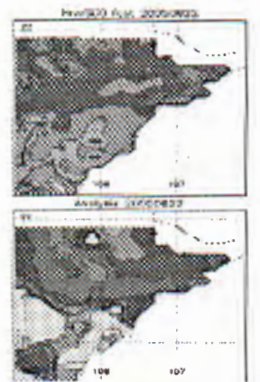

(a): H14-31/TK

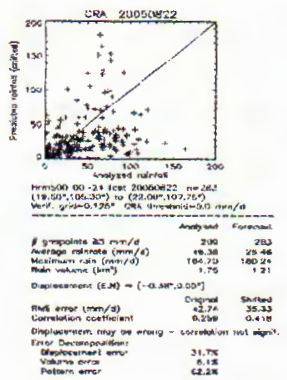

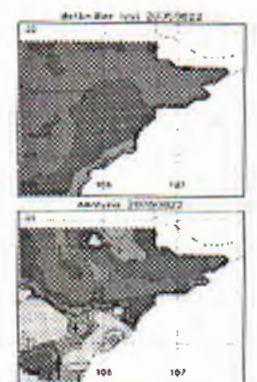

(b): H14-31/BMJ

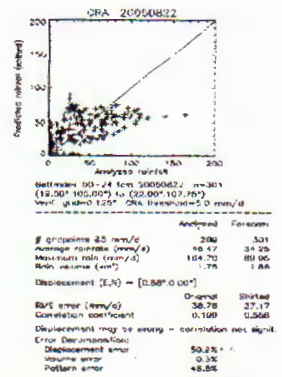

arted at 00Z21082005,

(a): H14-31/TK, (b): H14-31/BMJ, threshold $\geq 5 \mathrm{~mm} /$ day

From the tables (right bottom in Fig. 7) of CRA verification results we found that the area averaged rainfall of $\mathrm{H14}-31 / \mathrm{TK}$ is $25 \mathrm{~mm}$, of H14-31/BMJ is $\sim 34 \mathrm{~mm}$ and of measurements is $\sim 46 \mathrm{~mm}$ of the day $22 / 8 / 2005$. Their maxima are $180 \mathrm{~mm}, 90 \mathrm{~mm}$ and 165 $\mathrm{mm}$, respectively. The CRA verification also provides us with the distance at which have to shift the forecast rainfall area towards the observation area to have corrected (shifted) errors. In this case the RMSE of H14-31/TK decreased from $42.7 \mathrm{~mm}$ to $35.3 \mathrm{~mm}$ while the one of H14-31/BMJ from $38.8 \mathrm{~mm}$ to $27.1 \mathrm{~mm}$. The original correlation coefficient (CC) of $\mathrm{H} 14-31 / \mathrm{TK}$ is 0.259 and increased to 0.418 after shifting. The respectively $\mathrm{CC}$ of H14-31/BMJ are 0.199 and 0.558 . This verification results really show a prominence of the BMJ scheme in comparision with TK scheme.

The statistical CRA-verification of heavy rainfall forecasts in North East region during three years (2003-2005) was carried. Five main scores taken average with number of CRA are given in Part I of Table 1, in which the number of CRA shows that with the same weather situiations during those years H14-31/BMJ has 633 cases which satisfy CRA verification while $\mathrm{H} 14-31 / \mathrm{TK}$ only has 389 cases (244 cases lesser). After determing the displacement vector using CRA method and shifting rainfall forecast area towards the observation area, RMSE of two versions obviously decreases and CC increases, however, the scores of H14-31/BMJ remain better than those of H14-31/TK.

The volume error of $\mathrm{H} 14-31 / \mathrm{TK}$ is $11.3 \%$ which is greater than allowed error while this of $\mathrm{H14}-31 / \mathrm{BMJ}$ is $7.8 \%$ which is much lower than allowed error (allowed error is $10 \%$ ). This essence feature implies that the moisture equilibrium in the model H14-31/BMJ is much better than in the H14-31/TK. Besides, the volume error of H14-31/BMJ is nearly similar to that of LAPS $(5.0 \% \pm 0.3)$ (Table 1 , part II) and it is well known that LAPS is considered as a skillful rainfall forecast model of Australia.

The displacement error and the pattern error of $\mathrm{H} 14-31 / \mathrm{BMJ}$ are $46.1 \%$ and $46.1 \%$ and of $\mathrm{H} 14-31 / \mathrm{TK}$ are $42.9 \%$ and $45.8 \%$, respectively. These errors are in the range of allowed error limit. All the mentioned remarks allow us to say that H14-31/BMJ has better skill than H14-31/TK for rainfall forecast in the tropics.

\section{CONCLUSION}

Some remarks could be deduced from above verification results

H14-31 using Tiedtke scheme often underestimates rainfall of high thresholds and overestimates rainfall of low thresholds while H14-31 using BMJ scheme shows better scores both in the location and the amount of rainfall. 
Considering resolutions of model we can say that the higher the resolution is (such as H14-31), the better the mesoscale processes and local features would be captured, as well as the weaker role of moisture convergence for convective development would be responsible (the basis of Tiedtke scheme). The higher the model resolution is the better instability in the tropical deep convection is described, by which tropical rainfall is governed.

The QPF of H14-31/BMJ is better than those of H14-31/TK because of the higher resolution of H14-31 and tropical rainfall governmentally is caused by tropical deep convection which is described by $\mathrm{BMJ}$ scheme better than by Tiedtke sheme. Our verification results show that the heavy rainfall forecast skill of H14-31/BMJ in tropics is nearly similar to the skill of LAPS of Australia.

To use a regional weather forecast model developed for extratropics to the tropics as Vietnam, especially to forecast heavy rain it is vitally important to find a suitable CPS since convective precipitation mainly contributes to tropical precipitation.

\section{REFERENCES}

1. A. Arakawa, and W. H. Schubert, Interaction of a cumulus cloud ensemble with the large-scale environment. Part I. J. Atmos. Sci., 31 (1974) 674-701.

2. A. K. Betts, Non-precipitating cumulus convection and its parameterization. Quart. J. Roy. Meteor. Soc., 99 (1973) 178-196.

3. A. K. Betts, The scientific basis and objectives of the US convection subprogram for the GATE, Bull. Amer. Met. Soc., 55 (1974) 304-313.

4. A. K. Betts, Saturation point analysis of moist convective overturning. J. Atmos. Sci., 39 (1982a) 1484-1505.

5. A. K. Betts, Atmospheric Convective Structure and a Convection Scheme Based on Saturation Point Adjustment, Workshop on convection in large-scale models, $28 \mathrm{Nov}$. to $1 \mathrm{Dec}$. (1983b) ECMWF.

6. Boundary layer thermodynamics of a high-plains severe storm. Mon. Wea. Rev. 112 (1984) 2199-2211.

7. A. K. Betts, Mixing line analysis of clouds and cloudy boundary layers. J. Atmos. Sci., 42 (1985) 2751-2763.

8. A. K. Betts, A new convective adjustment scheme. Part I: Observational and theoretical basis. Quart. J. Roy. Meteor. Soc., 112 (1986) 677-692.

9. A. K. Betts, and M. J. Miller, A new convective adjustment scheme. Part II: Single column tests using GATE wave, BOMEX, ATEX and arctic air-mass data sets. Quart. J. Roy. Metear. Soc., 112 (1986) 693-709.

10. T. N. Krishnamurti, Summer Monsoon Experiment - A Review. Mon. Wea. Rev. 113 (1985) 1590-1626.

11. s. Manabe, J. Smagorinsky, and R. F. Strickler, Simulated climatology of a general circulation model with a hydrologic cycle, Mon. Wea. Rev. 93 (1965) 769-798.

12. J. L. McBride and E. E. Ebert, Verification of quantitative precipitation forecasts from operational numerical weather prediction models over Australia, Weather and Forecasting. 15 (2000) 103-121.

13. M. Tiedtke, A comprehensive mass flux scheme for cumulus parameterization in large-scale models, Mon. Wea. Rev., 117 (1989) 1779-1799.

14. A. William Gallus Jr. and Moti Segal, Impact of improved initialization of mesoscale features on convective system rainfall in 10-km Eta simulations. Weather and Forecasting 16 (2001) 680-696. 
15. T. X. Kieu et al., Research on application of high technological numerical models for prediction of storm movements over the South China Sea, Research Report of the National Separete Scientific Technological Project, ID: ĐTĐL- 02/2000, 2002. 184 p.

16. T. X. Kieu et al., Research and application of high technological numerical model system for heavy precipitation forecasting to serve flooding forecast, Research Report of the National Separete Scientific Technological Project, ID: ĐTĐL- 02/2002, 2005. 330 p.

Received January 26, 2007

\section{DỤ BÁO MƯA LớN ở VIṭ̂T NAM BẰNG MÔ HìNH H14-31 VớI SƯ DỤNG SƠ ĐỒ THAM SỐ HOẢ ĐỐI LƯU BETTS-MILLER-JANJIC}

Theo quan điểm của Krishnamurti, những cải tiến trong tham số hóa vật lý sẽ có tác động chủ yếu đến kết quả mô phỏng nhiệt đới [10]. Nghiên cứu của William A. Gallus Jr. cho thấy, với mô hình có độ phân giải cao và tham số hóa đối lưu tinh hơn thì kỹ năng dự báo mưa định lượng nói chung sẽ cao hơn [16]. Kết quả dự báo mưa rất nhạy đối với sơ đồ tham số hoá đối lưu cũng như độ phân giải mô hình. Thực tế cho thấy, đối với mô hình khu vực phân giải khá cao như H14-31 thì sơ đồ tham số hoá đối lưu dựa vào hội tụ âm mực thấp của Tiedtke đã không cho dự báo tốt mưa lớn ơ Việt nam. Trong bài báo này chúng tôi đã sứ dụng mô hình H14-31 với sơ đồ điều chinh đối lưu về thám sát nhiệt đới thực của Betts-Miller-Jajic thay cho sơ đồ Tiedtke. Đánh giá kết quả dự báo của H14-31 với hai sơ đồ trên bằng các phương pháp thống kê theo loại cũng như bằng thẩm định CRA trên từng trường hợp cũng như trên tập hợp dự báo ba mùa mưa (2003-2005) cho thấy, dự báo mưa lớn trên lãnh thổ Việt nam-Biển Đông của H14-31/BMJ tốt hơn hằn so với của H14-31/TK. Kết quả thẩm định CRA còn cho thấy, có thể coi H14-31/BMJ có kỹ năng dự báo mưa lớn nhiệt đới gần tương đương với kỹ năng của hệ thống mô hình LAPS của Úc. 